\title{
Cancer Registry Report in Mansoura University Hospital, Egypt in 2015
}

\author{
Research Article
}

Niveen A. Abo-Touk, M.D. ${ }^{1}$

${ }^{1}$ The Department of Clinical Oncology and Nuclear Medicine, Faculty of Medicine, Mansoura University, Egypt

Received 14 June 2017; Accepted 26 April 2019

\begin{abstract}
Background: This study aimed to report a cancer registry in Clinical Oncology and Nuclear Medicine Department, Mansoura University Hospital in 2015.

Patients and Methods: All cancer patients who were registered in the department of Clinical Oncology and Nuclear Medicine, Mansoura University Hospital in the time period from January $1^{\text {st }}, 2015$ to December $31^{\text {st }}, 2015$, were enrolled in this study. The data in the outpatient clinic index including patient's name, age, sex and diagnosis were collected.

Results: The included patients were 1146 males (43.7\%) and 1474 females (56.3\%), the male to female ratio was 1:1.3. The median age for patients was 54 years, and it ranged from 1.5 to 93 years. The median age at diagnosis for female and male patients was 52 years and 57 years, respectively. The most common sites for cancer in females were breast (47.2\%), thyroid (7.6\%), colon and rectum (5.7\%), non-Hodgkin (3.6\%), uterus, brain and then ovary. However, the most common cancer sites among males were bladder $(9.7 \%)$, colon and rectum $(9.2 \%)$, lung $(8.5 \%)$, hepatobiliary region $(7.9 \%)$, brain $(6.6 \%)$, non-Hodgkin lymphoma $(6.6 \%)$ and then prostatic cancer.

Conclusion: The current report provides a first cancer registry for this hospital based on data, to be further included in cancer statistics.
\end{abstract}

Keywords: Cancer registry • cancer report • Mansoura University Hospital • cancer in Egypt

\section{Introduction}

Based on the GLOBOCAN 2012, an increase to 19.3 million new cancer cases per year by 2025 was estimated due to the growth and ageing of the global population. More than half (56.8\%) of incident cancers and $64.9 \%$ of cancer deaths occurred in less developed regions of the world in 2012; that will increase by 2025. .1] $^{[1]}$

El-Mansoura is the capital of the Dakahlia governorate, which is an Egyptian governorate that is considered the base of the Nile Delta and lying in the north east of Cairo. Its area is about $3,500 \mathrm{~km}^{2}$ and it has a population of about 5,876,583 in January 2015, representing about $6.8 \%$ of the total population of the Republic. ${ }^{[2]}$

There were few available cancer rates at the national and regional levels of Egypt. The first cancer registries in Egypt were established in Alexandria and the National Cancer Institute in Cairo, and these were hospital-based. ${ }^{[3-5]}$ The Governorate of Gharbiyah had a population based cancer registry for 2000-2002, which was published in 2007. ${ }^{[6]}$ The National Cancer Registry Program (NCRP) was initiated in 2008; a populationbased registry was performed in the Ministry of Health Cancer Centers located in the 3 governorates to cover the Upper, Middle and Lower Egypt. The program started in the Governorate of Aswan, and then, registries were done in the Governorates of Damietta and Minia to be included in the program. Analyses of data from these registries were released in 2010. Based upon the results of the National Cancer Registry Program, the first Egyptian national cancer incidence rates report was published. ${ }^{[7]}$

Cancer patients from different areas were treated in Mansoura University Hospital, which has been for teaching and treating all cancer patients, but they were not included in any national cancer statistics or population based cancer registries. Hospital-based registries that 
concentrate on clinical care and hospital administration may help in assessing the public health requirements and affect control measures. ${ }^{[8]}$ So, the current study is aimed to report this hospital-based registry.

\section{Patients and Methods}

All the new cancer patients who were registered in the outpatient of the Clinical Oncology and Nuclear Medicine Department, Mansoura University Hospital, from January $1^{\text {st }}, 2015$ to December 31st 2015 , were enrolled in this study. The study was approved by the Ethical Committee of Faculty of Medicine, Mansoura University.

The data that was recorded in the outpatient index, including patient's name, age, sex and diagnosis, were used. All the data were assured and corrected through the patients' electronic sheets and accepted by the panel of the department. These data have been tabulated and subjected to statistical analysis. The cancer cases that reported in 2015 were stratified by age group and sex.

This study may not actually estimate the numbers of hematological cancers because not all the patients were referred to our department, and they had been treated in the medical department.

\subsection{Statistical analysis}

The data was analyzed using SPSS (Statistical Package for Social Science) program version 15. Descriptive data were calculated; the continuous variables were presented as mean, median and range, and the categorical variables were described using number and percent. The patients were classified into 5-years age groups. The cancer cases that were reported in 2015 were stratified by age groups and sex. The frequencies of different cancer sites for each gender and for each patient's age group were tabulated.

\section{Results}

During 2015, 2620 cancer patients were registered in Clinical Oncology and Nuclear Medicine Department, Mansoura University Hospital. There were 1146 males (43.7\%) and 1474 females (56.3\%); the male to female ratio was $1: 1.3$. The median age for the patients was 54 years, and it ranged from 1.5 to 93 years. The median age at diagnosis for females was 52 years and median age for males was 57 years.

There was increase in the frequency of cancer with increasing age for both males and females that was more apparent above 45 years with a decreasing incidence after the age group of 65 years (Figure 1). Amongst the female patients, the percentage of patients was the highest between age groups 45 and 60 years, while it was between 50 and 65 years in male patients (Figure 2, 3).

It was found that 103 patients $(3.9 \%)$ were below the age of 20 years (children and young adult), including 69 children less than 15 years old (2.6\% of patients); $61.2 \%$ of them were males and $38.8 \%$ were females. The number of patients over 65 years was 532 patients (20.31\%), $56.2 \%$ of them were males and $43.8 \%$ were females. However, above the age group of 20 years and below 65 years, female patients constituted $60.5 \%$ and male patients were $39.5 \%$ of patients (Figure 2, 3).

The most common sites for cancer in all the patients were breast $(27.0 \%)$, colon and rectum $(7.2 \%)$, thyroid $(5.9 \%)$, bladder $(5.0 \%)$, lung $(4.9 \%)$, non-Hodgkin lymphoma $(4.9 \%)$, brain and then hepatobiliary region $(3.9 \%)$. Among females, the most common sites were breast $(47.2 \%)$, thyroid $(7.6 \%)$, colon and rectum $(5.7 \%)$, non-Hodgkin (3.6\%), uterus, brain and ovary. However, the most common cancer sites among males were bladder $(9.7 \%)$, colon and rectum $(9.2 \%)$, lung $(8.5 \%)$, hepatobiliary region $(7.9 \%)$, brain $(6.6 \%)$, non-Hodgkin lymphoma (6.6\%) and prostatic cancer $(6.1 \%)$ (Table 1).

The distributions of cancer sites by patients' age group are represented in Table (2). Below the age of 15 years, brain was the most common site for cancer that was found in 18 children $(26.1 \%)$ out of the patients in this age group. Soft tissue sarcoma presented in 10 children $(14.5 \%)$, followed by acute leukemia in 9 children $(13.0 \%)$, then neuroblastoma in 8 children $(11.6 \%)$ and renal tumor in 7 children (10.1\%). However, between 15 and 19 years (young adult), acute leukemia had the highest frequency $(20.6 \%)$ of patient age group, NHL was found in 6 patients (17.6\%) and then soft tissue sarcoma was diagnosed in 4 patients (11.8\%) (Table 2).

111 patients (26.9\%) in age group 20-39 years had breast cancer, 66 patients $(16.0 \%)$ had thyroid cancer, and 36 patients $(8.7 \%)$ had brain tumor. These were followed in order by soft tissue sarcoma, colorectal cancer and then NHL in 18 patients $(4.4 \%)$ and acute leukemia in 17 patients (4.1\%). Whilst in male patients of this age group, brain tumor was the most frequent cancer that occurred in 23 patients $(18.0 \%)$. Thyroid cancer was found in 13 patients $(10.2 \%)$ followed by $\mathrm{NHL}$ in $12(9.4 \%)$ and colorectal in $11(8.6 \%)$, then acute leukemia and bone tumors that constituted $6.3 \%$ each.

Above the age of 40 years, breast cancer was also the most frequent cancer in female patients. However, among male patients in the age group 40-65 years, colorectal cancer (10.8\%), hepatobiliary (10.7\%) and 
Age group (years)

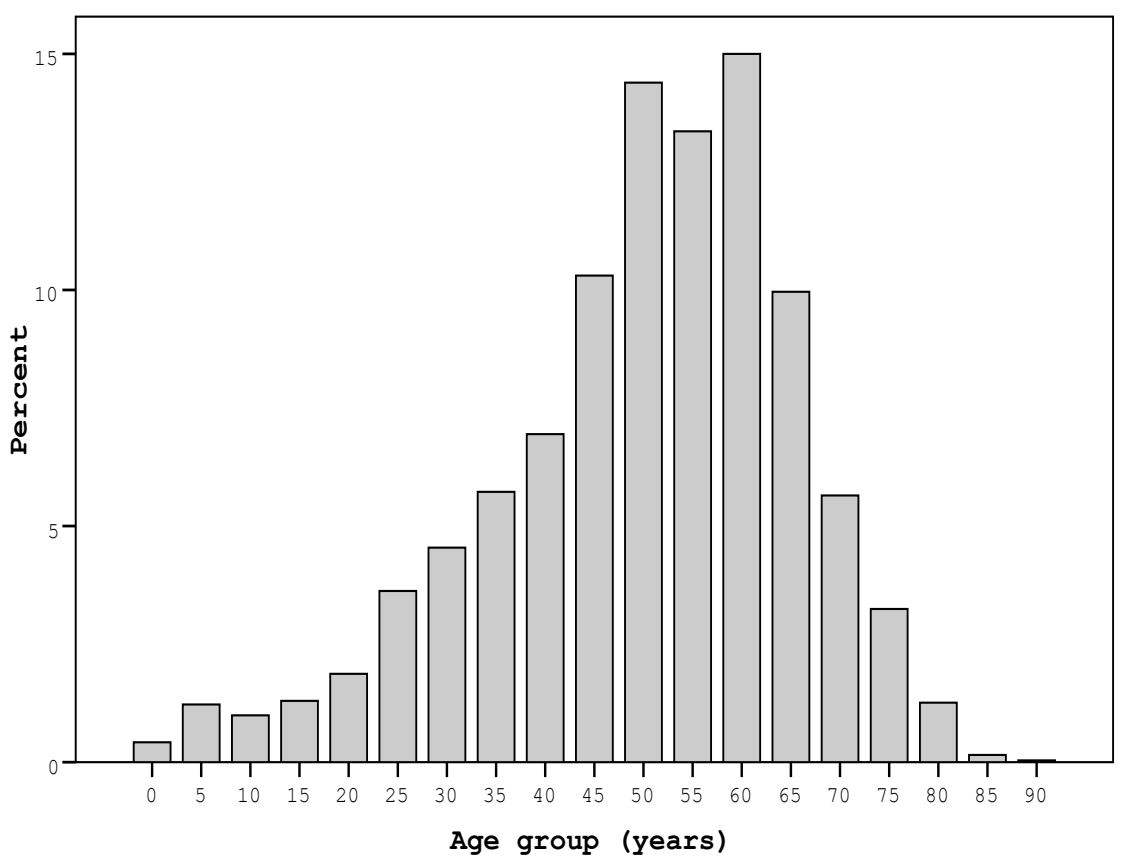

Figure 1: Distribution of patients in 5-years age groups.

Age group (years)

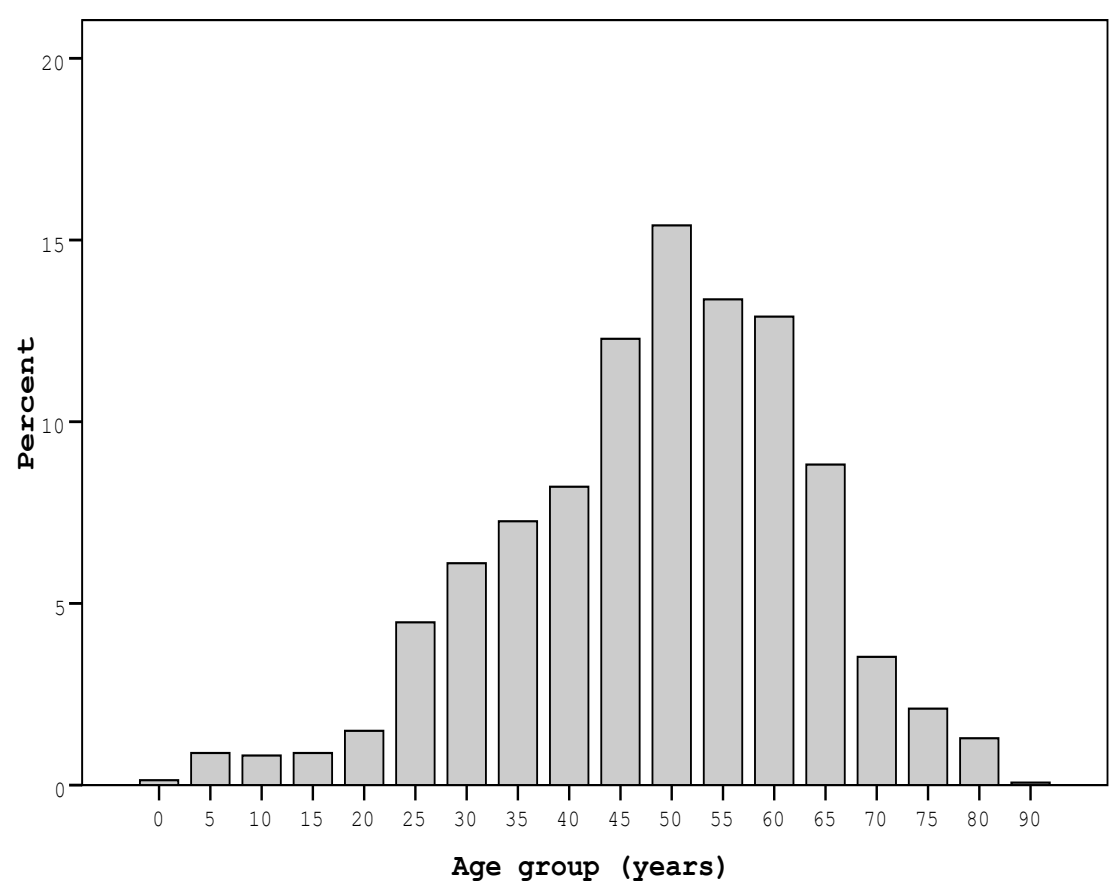

Figure 2: Distribution of female patients in 5-years age groups. 


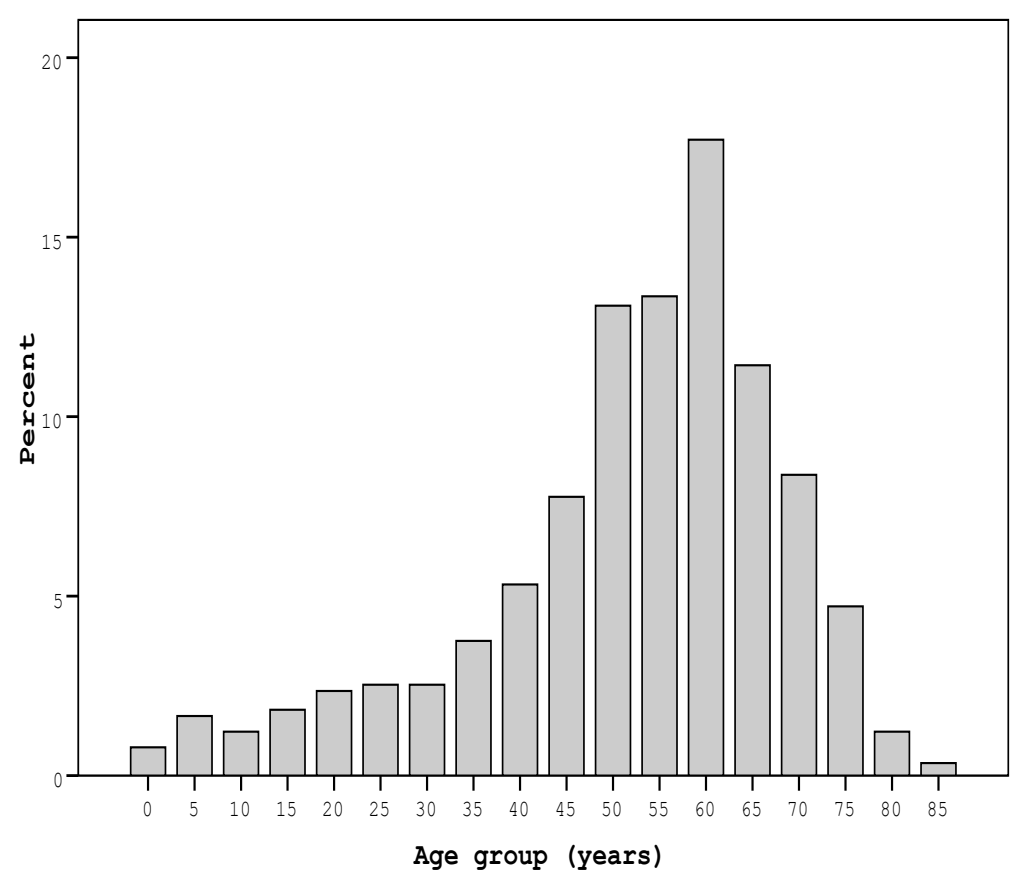

Figure 3: Distribution of male patients in 5-years age groups.

lung cancer $(10.5 \%)$ were the most frequent cancers, while in more than 65 years, bladder cancer $(22.0 \%)$ and prostatic cancer (14.3\%) were the commonest.

\section{Discussion}

The new cancer cases of our department in 2015 were provided and the most prevalent cancer sites for each ethnic group and sex were presented. There were 2620 cancer patients including 1146 males (43.7\%) and 1474 females (56.3\%), while the documented national age standardized incidence rates for cancers were $175.9 / 100,000$ for males and 157.0/100,000 for females. [7] The estimated number of new cases of invasive cancers that was expected in 2015 in the United States was a total of $1,658,370$ cases; 848,200 were males and 810,170 were female. ${ }^{[9]}$ This higher prevalence for cancer in female than male patients may be explained by the high percent of patients $(58.8 \%)$ in age groups between 25-55 years in which the number of female patients were more than males. Coinciding with the probability of developing invasive cancer in the United States from 2010 to 2012 that were higher for women $(5.4 \%)$ than for men $(3.4 \%)$ in adults aged younger than 50 years because of the relatively high burden of breast, thyroid and genital cancers in young women. ${ }^{[10,11]}$

It was found that 103 patients $(3.9 \%)$ were below the age of 20 years, including 69 children below 15 years old $(2.6 \%$ of patients); $61.2 \%$ of them were males and $38.8 \%$ were females. In Gharbiah Population-based Cancer Registry, during the period from January 2000 to December 2002, the number of cancer patients below the age of 20 years was 643 patients $(6.2 \%)$ of the total number. The children below 15 years were 460 patients, constituting $4.4 \%$ of all the incidents of cancer; $61.5 \%$ of them were males, $38.5 \%$ were females. ${ }^{[6]}$

In this report, the most common sites for cancer in all the patients were breast $(27.0 \%)$, colon and rectum $(7.2 \%)$, thyroid $(5.9 \%)$, bladder $(5.0 \%)$, lung $(4.9 \%)$, nonHodgkin lymphoma (4.9\%), brain and then hepatobiliary region. Worldwide, six cancers constituted $55 \%$ of the global incidence burden in 2012; lung cancer was the most common cancer in term of new cases (1.8 million cases, $12.9 \%$ of total). Breast cancer was the second most common cancer overall (1.7 million cases, $11.9 \%$ ), followed by colorectal cancer (1.4 million cases), prostate cancer (1.1 million cases), stomach cancer (951,000 cases) and liver cancer (782,000 cases). In more developed regions, just four cancers-female breast, prostate, lung and colorectum-comprised half of the total incidence, whereas in less developed 
Table 1: Frequencies of all the cancer sites by gender.

\begin{tabular}{|c|c|c|c|c|c|c|}
\hline The site of cancer & $\begin{array}{c}\text { Patients } \\
(\mathrm{n}=2620)\end{array}$ & $\begin{array}{c}\text { Total } \\
\text { percent }\end{array}$ & $\begin{array}{c}\text { Female } \\
(n=1474)\end{array}$ & $\begin{array}{l}\text { Female } \\
\text { percent }\end{array}$ & $\begin{array}{c}\text { Male } \\
(n=1146)\end{array}$ & $\begin{array}{c}\text { Male } \\
\text { percent }\end{array}$ \\
\hline Lip & 13 & 0.5 & 2 & 0.1 & 11 & 1.0 \\
\hline Tongue & 20 & 0.8 & 9 & 0.6 & 11 & 1.0 \\
\hline Oral cavity & 16 & 0.6 & 6 & 0.4 & 10 & 0.9 \\
\hline Salivary gland & 21 & 0.8 & 10 & 0.7 & 11 & 1.0 \\
\hline Ears & 1 & 0.0 & 0 & 0 & 1 & 0.1 \\
\hline Orbit & 3 & 0.1 & 0 & 0 & 3 & 0.3 \\
\hline Nasal cavity \&sinuses & 6 & 0.2 & 3 & 0.2 & 3 & 0.3 \\
\hline Nasopharynx & 19 & 0.7 & 6 & 0.4 & 13 & 1.1 \\
\hline Oropharynx & 4 & 0.2 & 4 & 0.3 & 0 & 0 \\
\hline Hypopharynx & 7 & 0.3 & 4 & 0.3 & 3 & 0.3 \\
\hline Larynx & 36 & 1.4 & 3 & 0.2 & 33 & 2.9 \\
\hline Esophagus & 19 & 0.7 & 10 & 0.7 & 9 & 0.8 \\
\hline Stomach & 47 & 1.8 & 21 & 1.4 & 26 & 2.3 \\
\hline Duodenum & 10 & 0.4 & 3 & 0.2 & 7 & 0.6 \\
\hline Colon \&Rectum & 189 & 7.2 & 84 & 5.7 & 105 & 9.2 \\
\hline Anus & 11 & 0.4 & 2 & 0.1 & 9 & 0.8 \\
\hline Hepatobiliary & 102 & 3.9 & 11 & 0.7 & 91 & 7.9 \\
\hline Pancreas & 100 & 3.8 & 40 & 2.7 & 60 & 5.2 \\
\hline Bone & 29 & 1.1 & 11 & 0.7 & 18 & 1.6 \\
\hline Skin & 34 & 1.3 & 11 & 0.7 & 23 & 2.0 \\
\hline Melanoma & 5 & 0.2 & 4 & 0.3 & 1 & 0.1 \\
\hline Soft tissue & 75 & 2.9 & 33 & 2.2 & 42 & 3.7 \\
\hline Kaposi sarcoma & 5 & 0.2 & 1 & 0.1 & 4 & 0.3 \\
\hline Breast & 707 & 27.0 & 695 & 47.2 & 12 & 1.0 \\
\hline Lung & 129 & 4.9 & 32 & 2.2 & 97 & 8.5 \\
\hline Pleura & 7 & 0.3 & 2 & 0.1 & 5 & 0.4 \\
\hline Thymus & 5 & 0.2 & 2 & 0.1 & 3 & 0.3 \\
\hline Thyroid gland & 155 & 5.9 & 112 & 7.6 & 43 & 3.8 \\
\hline Parathyroid & 1 & 0.0 & 0 & 0 & 1 & 0.1 \\
\hline Prostate & 70 & 2.7 & 0 & 0 & 70 & 6.1 \\
\hline Testis & 8 & 0.3 & 0 & 0 & 8 & 0.7 \\
\hline Kidney, pelvis, ureter & 27 & 1.0 & 9 & 0.6 & 18 & 1.6 \\
\hline Bladder & 131 & 5.0 & 20 & 1.4 & 111 & 9.7 \\
\hline Uterus & 45 & 1.7 & 45 & 3.1 & 0 & 0 \\
\hline Placenta & 8 & 0.3 & 8 & 0.5 & 0 & 0 \\
\hline Cervix & 30 & 1.1 & 30 & 2.0 & 0 & 0 \\
\hline Ovary & 41 & 1.6 & 41 & 2.8 & 0 & 0 \\
\hline Vulva & 9 & 0.3 & 9 & 0.6 & 0 & 0 \\
\hline Brain & 120 & 4.6 & 44 & 3.0 & 76 & 6.6 \\
\hline Pitutary gland & 2 & 0.1 & 1 & 0.1 & 1 & 0.1 \\
\hline Spinal cord & 2 & 0.1 & 0 & 0 & 2 & 0.2 \\
\hline Neuroblastoma & 8 & 0.3 & 5 & 0.3 & 3 & 0.3 \\
\hline Plasma cell & 38 & 1.5 & 17 & 1.2 & 21 & 1.8 \\
\hline Hodgkin lymphoma & 25 & 1.0 & 14 & 0.9 & 11 & 1.0 \\
\hline Non Hodgkin lymphoma & 129 & 4.9 & 53 & 3.6 & 76 & 6.6 \\
\hline Acute leukemia & 37 & 1.4 & 16 & 1.1 & 21 & 1.8 \\
\hline Chronic leukemia & 6 & 0.2 & 2 & 0.1 & 4 & 0.3 \\
\hline Myeloproliferative disorder & 3 & 0.1 & 1 & 0.1 & 2 & 0.2 \\
\hline Mycosis fungoids & 4 & 0.2 & 3 & 0.2 & 1 & 0.1 \\
\hline MUO & 101 & 3.9 & 35 & 2.4 & 66 & 5.8 \\
\hline
\end{tabular}

T Table 2.1 
Table 2: Frequencies of all the sites of cancer according to 5-years age groups.

\begin{tabular}{|c|c|c|c|c|c|c|c|c|c|c|c|c|c|c|c|c|c|c|}
\hline Site of cancer & Total & $0-$ & 5- & $10-$ & 15- & 20- & 25- & 30- & 35- & 40- & 45- & $50-$ & $55-$ & 60- & $65-$ & 70- & 75- & 80- \\
\hline Lip & 13 & 0 & 0 & 1 & 0 & 0 & 0 & 0 & 0 & 0 & 1 & 1 & 2 & 3 & 2 & 1 & 2 & 0 \\
\hline Tongue & 20 & 0 & 0 & 0 & 0 & 0 & 1 & 1 & 2 & 2 & 1 & 2 & 4 & 4 & 2 & 0 & 1 & 0 \\
\hline Oral cavity & 16 & 0 & 0 & 0 & 0 & 0 & 0 & 0 & 2 & 3 & 1 & 2 & 0 & 3 & 1 & 0 & 4 & 0 \\
\hline Salivary gland & 21 & 0 & 0 & 0 & 1 & 2 & 1 & 2 & 1 & 2 & 2 & 2 & 4 & 1 & 0 & 0 & 2 & 1 \\
\hline Ears & 1 & 0 & 0 & 0 & 0 & 0 & 0 & 0 & 0 & 0 & 0 & 0 & 1 & 0 & 0 & 0 & 0 & 0 \\
\hline Orbit & 3 & 0 & 0 & 0 & 0 & 0 & 0 & 0 & 0 & 0 & 0 & 1 & 0 & 1 & 0 & 0 & 0 & 1 \\
\hline Nose, sinus & 6 & 0 & 0 & 0 & 1 & 0 & 1 & 1 & 0 & 0 & 1 & 0 & 0 & 1 & 0 & 0 & 0 & 1 \\
\hline Nasopharynx & 19 & 0 & 0 & 0 & 3 & 0 & 1 & 0 & 0 & 2 & 2 & 7 & 1 & 2 & 1 & 0 & 0 & 0 \\
\hline Oropharynx & 4 & 0 & 0 & 0 & 0 & 0 & 0 & 0 & 0 & 0 & 0 & 3 & 1 & 0 & 0 & 0 & 0 & 0 \\
\hline Hypopharynx & 7 & 0 & 0 & 0 & 0 & 0 & 0 & 0 & 1 & 1 & 1 & 1 & 1 & 1 & 0 & 1 & 0 & 0 \\
\hline Larynx & 36 & 0 & 0 & 0 & 0 & 0 & 0 & 0 & 0 & 2 & 2 & 9 & 5 & 11 & 1 & 2 & 4 & 0 \\
\hline Esophagus & 19 & 0 & 0 & 0 & 0 & 0 & 0 & 0 & 2 & 2 & 1 & 1 & 4 & 2 & 4 & 2 & 1 & 0 \\
\hline Stomach & 47 & 0 & 0 & 0 & 0 & 0 & 0 & 4 & 3 & 4 & 5 & 5 & 7 & 9 & 6 & 2 & 2 & 0 \\
\hline Duodenum & 10 & 0 & 0 & 0 & 0 & 0 & 0 & 0 & 0 & 2 & 1 & 2 & 2 & 1 & 2 & 0 & 0 & 0 \\
\hline Colon \&Rectum & 189 & 0 & 0 & 0 & 0 & 2 & 7 & 2 & 11 & 14 & 23 & 20 & 31 & 40 & 23 & 8 & 5 & 3 \\
\hline Anus & 11 & 0 & 0 & 0 & 0 & 0 & 0 & 0 & 0 & 1 & 1 & 2 & 2 & 1 & 3 & 0 & 0 & 1 \\
\hline Hepatobiliary & 102 & 0 & 1 & 0 & 0 & 0 & 0 & 0 & 2 & 4 & 3 & 23 & 23 & 24 & 14 & 6 & 2 & 0 \\
\hline Pancreas & 100 & 0 & 0 & 1 & 1 & 0 & 2 & 1 & 2 & 7 & 18 & 14 & 14 & 23 & 7 & 6 & 1 & 3 \\
\hline Bone & 29 & 0 & 1 & 5 & 3 & 3 & 3 & 4 & 1 & 1 & 3 & 1 & 1 & 1 & 1 & 0 & 1 & 0 \\
\hline Skin & 34 & 0 & 0 & 0 & 0 & 0 & 0 & 2 & 0 & 2 & 1 & 4 & 5 & 7 & 2 & 7 & 1 & 3 \\
\hline Melanoma & 5 & 0 & 0 & 0 & 0 & 0 & 1 & 0 & 2 & 0 & 0 & 1 & 1 & 0 & 0 & 0 & 0 & 0 \\
\hline Soft tissue & 75 & 5 & 4 & 1 & 4 & 5 & 6 & 4 & 8 & 4 & 9 & 5 & 7 & 3 & 4 & 4 & 1 & 1 \\
\hline Kaposi sarcoma & 5 & 0 & 0 & 0 & 0 & 0 & 0 & 0 & 0 & 1 & 1 & 1 & 0 & 1 & 1 & 0 & 0 & 0 \\
\hline Breast & 707 & 0 & 0 & 0 & 0 & 2 & 13 & 40 & 56 & 68 & 107 & 144 & 99 & 87 & 58 & 19 & 9 & 5 \\
\hline Lung & 129 & 0 & 0 & 0 & 0 & 1 & 0 & 3 & 2 & 4 & 12 & 21 & 27 & 24 & 17 & 12 & 5 & 1 \\
\hline Pleura & 7 & 0 & 0 & 0 & 0 & 0 & 0 & 0 & 1 & 1 & 0 & 2 & 0 & 1 & 2 & 0 & 0 & 0 \\
\hline Thymus & 5 & 0 & 0 & 0 & 0 & 0 & 0 & 0 & 1 & 2 & 1 & 1 & 0 & 0 & 0 & 0 & 0 & 0 \\
\hline Thyroid gland & 155 & 0 & 0 & 0 & 2 & 6 & 21 & 21 & 18 & 13 & 17 & 14 & 15 & 10 & 7 & 6 & 2 & 3 \\
\hline Parathyroid & 1 & 0 & 0 & 0 & 0 & 0 & 0 & 0 & 0 & 0 & 0 & 1 & 0 & 0 & 0 & 0 & 0 & 0 \\
\hline Prostate & 70 & 0 & 0 & 0 & 0 & 0 & 0 & 0 & 0 & 0 & 2 & 3 & 7 & 15 & 19 & 13 & 7 & 4 \\
\hline Testis & 8 & 0 & 0 & 0 & 0 & 2 & 1 & 0 & 1 & 0 & 1 & 2 & 1 & 0 & 0 & 0 & 0 & 0 \\
\hline Kidney, ureter & 27 & 2 & 4 & 1 & 0 & 0 & 0 & 1 & 1 & 0 & 1 & 4 & 4 & 6 & 1 & 1 & 1 & 0 \\
\hline Bladder & 131 & 0 & 0 & 0 & 0 & 0 & 0 & 0 & 0 & 0 & 2 & 7 & 10 & 32 & 31 & 24 & 20 & 5 \\
\hline Uterus & 45 & 0 & 0 & 0 & 0 & 0 & 0 & 1 & 2 & 2 & 1 & 6 & 9 & 15 & 4 & 5 & 0 & 0 \\
\hline Placenta & 8 & 0 & 0 & 0 & 1 & 1 & 4 & 1 & 1 & 0 & 0 & 0 & 0 & 0 & 0 & 0 & 0 & 0 \\
\hline Cervix & 30 & 0 & 0 & 0 & 0 & 0 & 0 & 1 & 3 & 5 & 3 & 4 & 5 & 1 & 5 & 2 & 1 & 0 \\
\hline Ovary & 41 & 0 & 0 & 1 & 2 & 1 & 3 & 4 & 0 & 1 & 6 & 5 & 5 & 4 & 5 & 0 & 2 & 2 \\
\hline Vulva & 9 & 0 & 0 & 0 & 0 & 0 & 0 & 1 & 0 & 0 & 0 & 0 & 1 & 3 & 0 & 3 & 1 & 0 \\
\hline Brain & 120 & 3 & 8 & 7 & 1 & 8 & 9 & 9 & 10 & 7 & 10 & 20 & 12 & 10 & 4 & 1 & 1 & 0 \\
\hline Pitutary gland & 2 & 0 & 0 & 0 & 0 & 1 & 0 & 0 & 0 & 1 & 0 & 0 & 0 & 0 & 0 & 0 & 0 & 0 \\
\hline Spinal cord & 2 & 0 & 0 & 0 & 0 & 0 & 1 & 1 & 0 & 0 & 0 & 0 & 0 & 0 & 0 & 0 & 0 & 0 \\
\hline Neuroblastoma & 8 & 1 & 6 & 1 & 0 & 0 & 0 & 0 & 0 & 0 & 0 & 0 & 0 & 0 & 0 & 0 & 0 & 0 \\
\hline
\end{tabular}


Table 2: Frequencies of all the sites of cancer according to 5-years age groups.

\begin{tabular}{lccccccccccccccccccc}
\hline Site of cancer & Total & $\mathbf{0}-$ & $\mathbf{5 -}$ & $\mathbf{1 0}$ & $\mathbf{1 5}$ & $\mathbf{2 0}$ & $\mathbf{2 5}-$ & $\mathbf{3 0}$ & $\mathbf{3 5}$ & $\mathbf{4 0}$ & $\mathbf{4 5}$ & $\mathbf{5 0}$ & $\mathbf{5 5 -}$ & $\mathbf{6 0}$ & $\mathbf{6 5 -}$ & $\mathbf{7 0 -}$ & $\mathbf{7 5 -}$ & $\mathbf{8 0}-$ \\
\hline Plasma cell & 38 & 0 & 0 & 0 & 0 & 0 & 0 & 1 & 3 & 2 & 3 & 8 & 5 & 7 & 5 & 3 & 1 & 0 \\
Hodgkin lymph. & 25 & 0 & 2 & 2 & 1 & 4 & 7 & 1 & 3 & 2 & 1 & 0 & 0 & 0 & 1 & 1 & 0 & 0 \\
Non Hodgkin & 129 & 0 & 2 & 0 & 6 & 3 & 7 & 6 & 2 & 15 & 18 & 15 & 14 & 16 & 9 & 10 & 2 & 4 \\
Acute leukemia & 37 & 0 & 4 & 5 & 7 & 7 & 5 & 3 & 2 & 1 & 2 & 0 & 0 & 1 & 0 & 0 & 0 & 0 \\
Chronic leukemia & 6 & 0 & 0 & 0 & 0 & 0 & 0 & 0 & 0 & 2 & 0 & 0 & 0 & 2 & 0 & 1 & 1 & 0 \\
Myeloproliferative & 3 & 0 & 0 & 0 & 0 & 0 & 0 & 0 & 1 & 0 & 0 & 0 & 0 & 0 & 1 & 1 & 0 & 0 \\
Mycosis fungoids & 4 & 0 & 0 & 0 & 0 & 0 & 0 & 1 & 0 & 0 & 2 & 0 & 0 & 1 & 0 & 0 & 0 & 0 \\
MuO & 101 & 0 & 0 & 1 & 1 & 1 & 1 & 3 & 6 & 2 & 4 & 13 & 20 & 19 & 18 & 7 & 5 & 0 \\
Total & 2620 & 11 & 32 & 26 & 34 & 49 & 95 & 119 & 150 & 182 & 270 & 377 & 350 & 393 & 261 & 148 & 85 & 38 \\
\% & 100 & 4 & 1.2 & 1.0 & 1.3 & 1.9 & 3.6 & 4.5 & 5.7 & 6.9 & 10.3 & 14.4 & 13.4 & 15.0 & 10.0 & 5.6 & 3.2 & 1.5 \\
Female & 1474 & 2 & 13 & 12 & 13 & 22 & 66 & 90 & 107 & 121 & 181 & 227 & 197 & 190 & 130 & 52 & 31 & 20 \\
Male & 1146 & 9 & 19 & 14 & 21 & 27 & 29 & 29 & 43 & 61 & 89 & 150 & 153 & 203 & 131 & 96 & 54 & 18 \\
\hline
\end{tabular}

regions, lung, female breast, stomach and colorectal cancers with liver and cervical cancers constituted over half the incidence burden (54\%). ${ }^{[12]}$

Although lung cancer was the most common type among men, it ranked second in more developed regions (490,000 cases) after prostate cancer $(759,000$ cases). Cancers of the lung $(751,000$ cases), liver $(462,000$ cases) and stomach (456,000 cases) were more among males in less developed regions, representing 40\% of the new cancer cases. In women, breast cancer was the most common cancer diagnosed in more and less developed regions while cervical cancer was the second most common cancer in less developed regions $(445,000$ cases $)$ that ordered $11^{\text {th }}$ in more developed regions $(83,000$ cases $) \cdot{ }^{[12]}$

The 3 most commonly diagnosed cancers in women the United States in 2015 were breast, lung and bronchus, and colorectum, accounting for half of all the cases in women. Breast cancer alone was expected to account for $29 \%$ of the new cancers in women. The most common cancers were prostate $(26 \%)$, lung and bronchus (14\%), and colorectal cancer $(8 \%)$ accounting for about half of all the cases in men, with prostate cancer alone constituting $26 \%$ of the new diagnoses. [9] However, in our department, the most common sites among women were breast $(47.2 \%)$, thyroid $(7.6 \%)$, colon and rectum (5.7\%), non-Hodgkin disease (3.6\%), uterus, brain and ovary. The most common cancer sites among men were bladder $(9.7 \%)$, colon and rectum $(9.2 \%)$, lung $(8.5 \%)$, hepatobiliary region $(7.9 \%)$, brain $(6.6 \%)$, non-Hodgkin lymphoma $(6.6 \%)$ and prostatic cancer (6.1\%). The low incidence of lung cancer may be due to a lesser exposure to smoking and carcinogens, as smoking in female is not a habit in our community, except in some of very high and very low socioeconomic standards, in addition to perhaps genetic factors. The higher figure of prostate cancer in the United States is related to screening and early detection, which is deficient in our area and is discovered accidentally or is neglected until it needs management in an advanced stage.

In Egypt, liver and bladder cancers constituted 44\% of all the cancer cases in males followed by lung (5.7\%), $\mathrm{NHL}$, brain and prostate (that occurred only in $4.3 \%$ of patients); in addition to that, breast and liver cancer represented $45 \%$ of all cancers in females followed by brain, ovary, NHL and thyroid (3.3\%). It was found that incidence rates showed differences between the 3 geographic regions of Egypt, in which the proportion of liver cancer in male was the highest in Lower Egypt (41.7\%) and next in Middle Egypt (20.4\%) and the lowest in Upper Egypt (11.8\%). Moreover, bladder cancer followed liver cancer in Lower Egypt (8.8\%), while in Upper Egypt, liver cancer was still the most common cancer. Among females, the proportion of liver cancer was the highest in Lower Egypt (16.4\%), then in Middle Egypt, and the least in Upper Egypt (8.9\% and 5.1\%, respectively), owing to the difference in the distribution of $\mathrm{HCV}$, which was more frequent in the Nile delta that decreased while going southwards. ${ }^{[13]}$

This result revealed a higher prevalence of thyroid cancer and a lower prevalence of hepatocellular carcinoma in our patients who might be treated medically due to associated liver cirrhosis, and so, they were not referred to receive active anticancer treatment. The was a miscalculation in the estimation of the prevalence of 
hematologic and liver cancer patients who were treated in the medical department. ${ }^{[7,8]}$

In our patients, brain tumor was the most common cancer below the age of 15 years that was found in 18 children $(26.1 \%)$. It was followed in order by soft tissue sarcoma presented in 10 children (14.5\%), acute leukemia in 9 children $(13.0 \%)$, neuroblastoma in 8 children (11.6\%) and renal tumor in 7 children (10.1\%). However, in the age group between 15-19 years (young adult), acute leukemia had the highest frequency accounting for $20.6 \%$ of the patients in this age group. $\mathrm{NHL}$ was found in 6 patients $(17.6 \%)$, followed by soft tissue sarcoma, which was diagnosed in 4 patients (11.8\%). In Gharbiah Registry, the commonest pediatric tumors (below 15 years) were lymphoma and leukemia (28.7\% and $24.3 \%$, respectively), CNS tumors were $10.9 \%$, malignant bone tumors were $(5.8 \%)$, soft tissue were tumors $(5.6 \%)$, renal tumor constituted $3.9 \%$ of all the cancer cases in children below 15 years. ${ }^{[6]}$ These lower percentages in our results of hematologic cancers patients that owing to be treated in pediatric department.

\section{References}

[1] Cancer IAfRo. Latest world cancer statistics Global cancer burden rises to 14.1 million new cases in 2012: Marked increase in breast cancers must be addressed. World Health Organization. 2013;12.

[2] Dakahlia Governorate Sis. Your gateway to Egypt. 2016.

[3] Sherif MS, Zarate A, Ibrahim AS. The profile of cancer in Egypt: final report of the Cancer Registry for the Metropolitan Cairo Are (CRMCA), 1972-1987. Cairo University, National Cancer Institute, Cancer Registry for the Metropolitcan Cairo Area; 1987.

[4] El-Attar I. Cancer statistics, NCl, 2004. Department of Biostatics and Epidemiology, $\mathrm{NCl}$, Egypt, December. 2005.

[5] Abou-Zeid W, El-Khwsky F, Mokhtar S, Sherif M, Mahdy N. Descriptive epidemiology and multivariate survival analysis of oral and pharyngeal malignancies in Alexandria. Journal of the Medical Research Institute. 2006;27(4):262-70.

[6] Ibrahim A, Seif-Eldin I, Ismail K, Hablas A, Hussein $H$, Elhamzawy $H$. Cancer in Egypt, Gharbiah: Triennial Report of 2000-2002, Gharbiah Population-based Cancer Registry. Cairo: Middle East Cancer Consortium. 2007.

[7] Ibrahim AS, Khaled HM, Mikhail NN, Baraka $\mathrm{H}$, Kamel $\mathrm{H}$. Cancer incidence in Egypt: results of the

\section{Conclusion}

This current report provided a first cancer registry from this hospital based data to be further included in cancer statistics. We need one registration number for all cancer patients by using the National ID that has not been completely established to be used in the following reports.

\section{Conflict of interest}

There is no conflict of interest.

\section{Acknowledgments}

We would like to thank all the patients, professors, doctors, deputies, residents and all staff members in the department of Clinical Oncology and Nuclear Medicine Department, Mansoura University Hospitals.

national population-based cancer registry program. Journal of cancer epidemiology. 2014;2014.

[8] Santos SI. Cancer epidemiology, principles and methods. Cancer epidemiology, principles and methods. 1999.

[9] Siegel RL, Miller KD, Jemal A. Cancer statistics, 2015. CA: a cancer journal for clinicians. 2015;65(1):5-29.

[10] Silbermann M, Freedman LS, Al-Kayed S, Barchana M, Boyiadzis M, El-Najjar K et al. Cancer registration in the Middle East. Medical Journal of Islamic Academy of Sciences. 1999;12(2):55-6.

[11] Siegel RL, Miller KD, Jemal A. Cancer statistics, 2016. CA: a cancer journal for clinicians. 2016;66(1):7-30.

[12] Ferlay J, Soerjomataram I, Dikshit R, Eser S, Mathers C, Rebelo M et al. Cancer incidence and mortality worldwide: sources, methods and major patterns in GLOBOCAN 2012. International journal of cancer. 2015;136(5):E359-86. doi:10.1002/ ijc. 29210.

[13] Ezzat S, Abdel-Hamid M, Eissa SA-L, Mokhtar $\mathrm{N}$, Labib NA, El-Ghorory $\mathrm{L}$ et al. Associations of pesticides, $\mathrm{HCV}, \mathrm{HBV}$, and hepatocellular carcinoma in Egypt. International journal of hygiene and environmental health. 2005;208(5):329-39. 